\title{
Research on the Relationship between Public Information Needs, Government Trust and Impact Mechanism under the Blockchain Industry
}

\author{
Qian $\mathbf{L i}^{*}$ \\ Anhui Jianzhu University, HeFei, Anhui, China \\ Urban management research center of Anhu Jianzhu University, HeFei, Anhui, China \\ *Corresponding Author.
}

\begin{abstract}
In view of the low utilization rate of "Internet + government" service users and the weak awareness of public participation, the paper analyzes the influencing factors of "Internet + government" Public Adoption in the context of blockchain technology from three dimensions: An accurate disclosure of information in an epidemic is conducive to enhancing the credibility of the government. From the perspective of a positive interaction between the government and the public under the background of blockchain industry, the paper analyzes the relationship between information needs and the trust of the government and the mechanism of influence in the context of a major epidemic. Based on the basic model of TAM and trust theory, a theoretical model of government trust influencing factors was constructed, and the applicability of the model was tested by using empirical research methods of questionnaires and structural equations. Research shows that factors such as openness and transparency of information, information security and reliability, and the ability of government information services significantly affect government trust. According to the research results, it is proposed to use block-chain technology to promote Chinese government information disclosure and rebuild the government trust system, which provides a more feasible theory and method for achieving government governance innovation under the background of blockchain industry.
\end{abstract}

Keywords: Major epidemic, government trust, blockchain industry, information needs

\section{Introduction}

When encountering public emergencies, especially infectious diseases that endanger the safety of human life, a positive interaction between the government and the public is the key factor to build the confidence of the whole society in order to successfully fight against the epidemic. Such interaction not only depends on the release of information accurately and timely but also requires the government and the public to reach a mutual trust based on information sharing mechanism. "Internet + government" model is not only a place of expressing public feeling and opinion but also a way to facilitate the communication between the government and the public. To adapt to the new administrative ecotope, the government should change the management model, standardize the "Internet + government" information service, strengthen the transparency of government information, and rebuild the trust in the government, to build a true "Responsive Government in the Sunshine". In 2018, the State Department issued a notice to deepen the "Internet+ government", asking for the further reform of "One Portal, One Door, Once Only", and the application of new technology such as "Internet, Big Data, and block-chain" to further strengthen the openness, transparency, and efficiency of government service. The disclosure of Government information is an important element to boost the modernization of national digital governance, achieve the trust and efficient operation of the government. Under the major epidemic situation, how to meet the demands of information from the public, with the adoption of block-chain technology, to make the disclosure more transparent, open, interactive, and participatory. Therefore, it is of great theoretical and practical value to analyze the relationship between the public information demand and the government trust in the context of the coronavirus epidemic and the establishment of government information service and trust system in terms of block-chain technology.

\section{The Status of Research in Block-Chain Technology Applying to Information Disclosure and Government Trust}

ISSN: 0010-8189 
Government trust refers to the public's reasonable expectation on government organization's undertaking the public responsibility and realizing the public interest, it also includes the public's expectation on government and its administration staff's responding to the social and public demands, such expectation affects the public's emotion and behavior [3, 4]. The scholars at home and abroad studied the factors of government trust based on the trust theory. Some scholars stated that users' trust plays a key intermediary factor between the needs and the behavior of the users $[5,6]$. The research of government trust mainly focuses on three aspects: the public's perception of service capability, information security, and transparency. The perception of service capability refers to the public's positive psychology and attitude towards government service at the level of public expectation and cognition, it reflects the public's subjective evaluation on the government's willingness and ability to provide an excellent service, as well as the public's expectation towards the government to deepen the reformation in order to provide a higher-quality service. The higher efficiency of government perceived by the public, the more public will recognize the capability of government staff $[7,8]$. The perception of information security refers to that online services such as tax payment and personal identity authentication, the network security factors will affect the public's trust on the government directly, and those factors will affect the public's attitude and behavior towards using government services indirectly as well $[9,10]$. The perception of information openness and transparency refers to that the more open and transparent the government service information is, the more willing the public is to understand and accept all kinds of administrative decisions of the government and evaluate the government behavior more objectively. At the same time, the more interaction between the public and the government, the more trust the public has in the government [11].

The research of block-chain technology applied in government trust mainly focuses on theoretical discussion and practical application. Due to the low transparency of government information and the low participation of the public in the government affairs, the public trust in the government is devalued, which to some extent damages the image of the government and even causes the failure in government trust. By applying the block-chain technology in constructing the government trust, the government can improve the transparency, security, and reliability of governance information system [12]. In terms of theoretical research, some scholars believed that building a government information trust system with the help of block-chain technology will not only satisfy the needs of convenience and timeliness from public's accessing to government information but also satisfy public's trust in government's ability to optimize public services[13,14]; some scholars stated that block-chain's point-to-point mechanism can avoid the failure in governance's data transmission, which meets the public's demand on the government's public information service capability [15,16]. In terms of practical application research, Bi Ruixiang [17] believes that the application of block-chain technology to the fields of e-government, such as citizenship authentication, integrity management, cadre and personnel file management, can develop users' interactive experience and their stickiness, improve the relationship between the government and the public, and push the government to provide efficient and high-quality services for the public, all these will enhance the trust in the government. Wang Maolu and Lu Jingyi [18] have analyzed the application of block-chain technology in social governance and government public affairs. They believe that block-chain technology will innovate government digital management and government management model, but will also face challenges from current institutional system, technical supervision, and other aspects. Ren Ming, Tang Hongbo [19], etc. analyzed the application of block-chain technology in foreign government departments, such as Russia, the United States, Australia, and other countries, pointed out that attention should be paid on the security, confidentiality, large file data storage, and other issues in the process of block-chain application, they also presented corresponding solutions.

To sum up, the existing literature mainly discusses the formation mechanism of government trust and the application of block-chain technology in government trust and social management, which provides some reference value for this study, but there are still some limitations: from one side, most of the existing literature analyzes the government information-sharing system, governance path and public responsibility mechanism from the macro-level of government trust, However, the micro-level of public information needs is rarely involved; Since developing the micro-level "Internet + government affairs" information disclosure is an important factor to realize the modernization of national digital governance, government trust, and efficient operation, it is urgent to introduce block-chain technology to improve the public's trust in the government. On the other side, many of the existing

ISSN: 0010-8189 
literature study the influencing factors of trust from a single dimension, ignoring the multidimensional influencing factors, moreover, above analysis of the influencing mechanism of trust is not clear. The application of block-chain technology determines the level of the "Internet + government" service, it also plays an important role that affects government trust. This study integrates block-chain technology with government information services, analyzes the factors that affect government trust in the coronavirus pandemic, and discusses the construction of a government trust system based on block-chain technology, the study will guide to improve the relationship between the government and the public, enhance the enthusiasm and initiative of the public to participate in government services, to achieve the purpose of building a better government reputation image.

\section{Analysis of the Relationship between Information Needs and Government Trust}

3.1 Advantages of block-chain technology in information disclosure:

The technical characteristics of block-chain, such as decentralization, openness, and transparency, privacy protection, traceability, etc., have advantages in government information services. The following analyzes the main similarity between block-chain and the construction of trust government system from the level of public need on information disclosure, the level of public participation and multi-participants, and the level of government trusting.

The level of public demand for information disclosure: the technical characteristics of block-chain, such as transparency and credibility, modification-proof, traceability, and security, are perfect to the transparency of information disclosure and these characteristics provide a safe and reliable environment for the construction of government trust. As the main body of social governance and public service, whether the government's management processing is open and transparent will not only affect the quality of public service but also affect the public's trust in the government. On the one hand, the distributed storage function of the block-chain enables each participant in the block-chain network to read and store data, update the whole network synchronously, and allow data sharing among different departments, so as to realize the openness and transparency of data among the government, society and the public. On the other hand, the application of block-chain's non-modification and traceable features used in works such as property protection, education, notarization, logistics, medical treatment, and voting can optimize the processes, improve collaboration efficiency, and effectively reduce operating costs and trust costs.

The level of public participation and multi-participants: the decentralized and distributed storage features of block-chain are propitious to the benign interaction between the government and the public, and fundamentally establishing the mass basis of government trust. As a public policymaker and public service provider, the government should focus on public interests, respect public rights, fulfill public responsibilities, promote social equity, and increase social welfare. Through block-chain technology, we can effectively achieve multi-center participation and multi-participants governance, making each participant in a relatively equal position, changing the once absolute central position of the government in the national governance system, to ensure the information symmetry and data autonomy between each party, and fundamentally rebuild the benign interaction and trust between the government and the public. The distributed storage feature of block-chain can make the participants of government system enjoy relatively equal rights, share data resources and fulfill their obligations, and realize mutual restraint and mutual supervision. Thus, we can form a decentralized data autonomous network, making the "Internet + government" system fairer, just and credible.

The level of Government Trust: the distributed storage and consensus mechanism of block-chain is propitious to promoting the decentralization of power, and it can guarantee the government trust through the restriction of government power. The traditional government organizational structure presents a centralized pyramid. The government in the system center has a dominate power on data resources and data governance power. The decision-making of data is entirely decided by the system center: that is, government has the right to decide whether the data be open or not and whether the data be shared with the public. This makes the information between the public and the government asymmetric, put the public at a weak side. Through the distributed storage feature, the participants in the system can have the equal power to access to information resources, and fulfill their obligations.

ISSN: 0010-8189 
Each party follows mutual restraint and mutual supervision, forming a decentralized network of data autonomy, making the "Internet+ government" service more fair, just and credible, thereby promising the trust in the government.

3.2 Research on the hypothesis of influencing factors of government trust

Government trust is the foundation of government establishing a good image. It is influenced by many factors, such as the level of government service, the transparency of government information disclosure, the degree of information security, and the degree of benign interaction between the government and the public. These factors are very important for the construction and maintenance of government trust. This paper analyzes the influencing factors of government trust from the following aspects: the public's perceived trust to the transparency of government information disclosure, the perceived trust to the information security, the perceived trust to the government's information serviceability, and the trust tendency towards the government.

Trust and public's willingness to adopt: as for the relationship between trust and public's willingness to adopt, some scholars believe that factors of user's trust will directly affect public's willingness to adopt, and the trust plays a key intermediary role between needs and usage behavior [20, 21]; Zhu duogang and Guo Junhua [22] analyzed the key factors affecting the public adoption of mobile administration and found that perceived trust and IT self-efficacy can significantly affect the public adoption intention. QianLi [23] analyzed the factors influencing the adoption of "Internet + government" affairs, and found that government trust and Internet technology trust affect users' initial acceptance intention. Xu Xiaolin, Zhang Ziyan and Ming Chenghan [24] studied the logical relationship between public trust, government service quality and intention of sustainable use, and found that public trust significantly affected government information quality, system quality, and service quality, thus affecting the intention of sustainable use of the public. According to the above literature analysis, public trust in the government will directly affect the willingness of the public adoption. Hereby, the following hypotheses proposed as:

Hypothesis H1: The public's trust in the government will affect the public's willingness to adopt. The public's perceived trust in the transparency of government information.

In the case of coronavirus pandemic, if the government followed an old method of public opinion governance with concept of "sealing, blocking and preventing", It could not prevent the break out of the public trust crisis in time, and more likely, incurred the side-crisis of trust caused by the response to Silence, these will aggravate the panic of the public on the epidemic events, resulting in a negative social mentality of the public, destroying the credibility of the government. By improving the transparency and availability of government information and removing the obstacle of communication between the government and the people, the government will improve the relationship between the government and the public, will help the public understand the actions from the government, and then generate public trust in the government. In view of the above discussion, the following hypotheses proposed as,

Hypothesis H2: The perceived trust in the public on the transparency of information disclosure will affect the public's trust in the government.

Public perception trust in information security: including public perception of information security and personal privacy protection. According to the existing literature, trust in information security is a key factor for users to adopt the "Internet+ government services", and also affects public trust in government. Information security is mainly concerned in the interaction between the public and the "Internet+ government" platform, and all kinds of information such as personal identity information, pension account, and transaction record should be protected. Due to the anonymity and virtuality of Internet, the public often has doubts about their personal privacy and security in the process of online interaction. Such lack of trust will affect the usage behavior of the public. In conclusion, the following hypotheses is proposed.

Hypothesis H3: The public's perceived trust in information security will affect the trust in the government.

ISSN: 0010-8189 
The perceived trust in government's information serviceability: the trust in the government's information serviceability is the public's subjective cognition to the government's public serviceability, as well as the judgment to the value of government's credit, which includes the public's trust in government's serviceability and government's credibility. The public's recognition of the government's information service capability refers to the public's belief that the government has sufficient human and technical resources on the information service to ensure the stability and security of the service, and the honest and open interactive service experience will also improve the public's trust in the government. In conclusion, the following hypotheses is proposed.

Hypothesis H4: Perceived trust in government information service capability will affect public trust in government. Trust tendency: due to the difference of psychological factors, education level and professional characteristics of users, their trust tendency will be affected by these characteristics; at the same time, due to some characteristics of users themselves, this trust also involves their own psychological factors, education, professional characteristics, etc. Trust tendency reflects the general tendency of individuals to trust others. Some scholars have pointed out that trust tendency refers to a person's consistent tendency to rely on others, which does not change with environment and trust objects, that is, trust is the expression of individual psychological characteristics, not affected by the government, social organizations, etc. [1]. The trust tendency comes from the two dimensions: human faith and trust position, which was put forward by McKnight and chervany [2]. When the services provided by the government platform provide convenience for the public, the personal trust tendency will affect user's trust in the government service, and at the same time, it will directly affect his perceptional trust in the information openness and transparency, trust in the information security and trust in the government information serviceability, and then indirectly affect the individual's trust in the government. In view of the above discussion, the following hypotheses is proposed,

Hypothesis H5: The tendency of trust will affect the perceived trust in the public on the transparency of information disclosure.

Hypothesis H6: The tendency of trust will affect the perceived trust in the public on information security.

Hypothesis H7: The tendency of trust will affect the public's perceived trust in the government's information serviceability.

Hypothesis H8: The tendency of trust will affect the public's trust in the government.

\subsection{Construction of government trust model}

Based on above literature analysis and theoretical assumptions, and the theories of trust, technology acceptance, and continuous usage of information systems, this paper selects the factors such as public perception trust in information transparency, information security, and government information serviceability, analyzes the mechanism of government trust, and constructs a trust factor model, as shown in Figure 1. This model assumes that government trust will significantly affect the public's willingness to adopt the "Internet+ government".

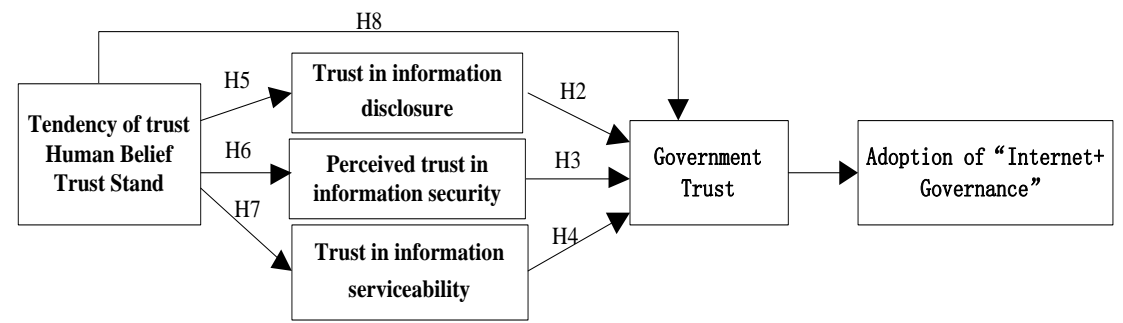

Fig 1: Government trust factor model

\section{Empirical Research}

ISSN: 0010-8189

(C) CONVERTER 2020 


\subsection{Questionnaire design and data collection:}

This paper collects data by means of an online questionnaire. When designing the respondents, the gender, age, education, and employment of the respondents are taken into account. The respondent are from seven provinces and cities in East China, covering Shanghai, Jiangsu, Hefei, Nanjing, Hangzhou, Nanchang and Fuzhou, who have the experience of conducting affairs in the government service center or logging into the e-government platform, the respondents are required to answer a list of questions with clear attitude, such as the evaluation of government information security trust, information disclosure perception, information serviceability, information technology application satisfaction. The questionnaire uses: a Likert 5 scale: "1": not interested, "2": not concerned, "3": agrees, "4": initially accepted, and "5": continuously use. In this survey, 3200 questionnaires were collected in total, and 3008 effective questionnaires were finally adopted after removing the invalid ones, with an effective adoption rate of about $94 \%$. In the effective questionnaire, $57 \%$ were men and $43 \%$ were women; $62 \%$ were undergraduates and above in education level; $45 \%$ were company employees in the public occupation; $28 \%$ in social organization. This paper mainly analyzes the influencing factors of government trust from the public's perception of trust in information openness and transparency, information security, and information serviceability. The definition of each variable is as Table 1.

Table 1 Main measurement variables

\begin{tabular}{|c|c|c|}
\hline Variable & observation variable and item & reference \\
\hline $\begin{array}{l}\text { Information } \\
\text { transparency, } \\
\text { Perceived trust }\end{array}$ & $\begin{array}{l}\text { I think the government has an open channel for } \\
\text { information disclosure } \\
\text { I think the government can open information actively and } \\
\text { timely. } \\
\text { I think the government information is open, true, and } \\
\text { accurate. } \\
\text { I think the government service process is transparent and } \\
\text { open. }\end{array}$ & $\begin{array}{l}\text { Wang Lianwei [3] } \\
\text { Liu Jianping, Zhou } \\
\text { Yun [4] } \\
\text { Venkatesh\&amp; } \\
\text { Davis [5]. }\end{array}$ \\
\hline $\begin{array}{l}\text { Information } \\
\text { security } \\
\text { awareness trust }\end{array}$ & $\begin{array}{l}\text { I think the service center technology is reliable. } \\
\text { I think the technical system of the service center is stable. } \\
\text { I think the service center can guarantee personal privacy. }\end{array}$ & $\begin{array}{l}\text { Cyan\&amp; Price [6]. } \\
\text { Rui Guoqiang, Song } \\
\text { Dian [7] } \\
\text { Zhu Chunkui, Mao } \\
\text { wanlei [8] }\end{array}$ \\
\hline $\begin{array}{l}\text { Perceived trust } \\
\text { in government } \\
\text { information } \\
\text { service ability }\end{array}$ & $\begin{array}{l}\text { I think the government has the ability to deal with } \\
\text { emergencies. } \\
\text { I think the government can solve the main social problems } \\
\text { effectively. } \\
\text { I think the government can respond to the concerns of the } \\
\text { masses in a timely manner. } \\
\text { I think government agencies are efficient, honest, and fair. }\end{array}$ & $\begin{array}{l}\text { Lu Xin, Pei Ruimin, } \\
\text { Liu Fan [9] } \\
\text { Que Tianhao [10] } \\
\text { Yu Yimin, Chen } \\
\text { Taowei [11] }\end{array}$ \\
\hline
\end{tabular}




\begin{tabular}{l|l|l}
\hline & $\begin{array}{l}\text { I believe the government can provide good services. } \\
\text { Government }\end{array}$ & $\begin{array}{l}\text { I think the government will defend our interests. } \\
\text { I think the administrative power of the government is [12] } \\
\text { restricted and supervised by law. }\end{array}$ \\
$\begin{array}{l}\text { I think the regional government departments are } \\
\text { trustworthy. }\end{array}$ & $\begin{array}{l}\text { Yun [13] } \\
\text { Qi Xuexiang [14] } \\
\text { Zhang Yi, Zhu Yi [15] }\end{array}$ \\
\hline
\end{tabular}

\subsection{Empirical analysis}

In the empirical analysis, SPSS and LISREL statistical tools are used to process the questionnaire data, by using the structural equation path coefficient to analyze the influence degree of variables in the participation model. And through the reliability, validity, and factor analysis, we can verify the relevance between the hypothetical variables.

\subsubsection{Reliability and validity analysis}

Cronbach's alpha internal consistency coefficient was used to test the reliability of the sample data, as shown in Table 2. After removing the items variable that CITC value less than 0.5 and keeping the items that CITC value greater than 0.6, the Cronbach's value of each item falls between 0.778 and 0.865, and the overall Cronbach's at the value of the questionnaire is 0.940 . It can be seen that the questionnaire has good internal consistency, indicating that the measurement data has good reliability, therefore the reliability of the measurement system in this study is acceptable.

Table 2 Reliability Statistics of Measurement Variables

\begin{tabular}{|c|c|c|}
\hline Variable & Cronbach's Alpha & Items \\
\hline Trust Tendency & 0.830 & 4 \\
\hline Perceived trust in information disclosure & 0.785 & 4 \\
\hline Perceived trust in information security & 0.865 & 3 \\
\hline Perceived trust in information serviceability & 0.778 & 4 \\
\hline Government Trust & 0.814 & 4 \\
\hline Adoption Intention of "Internet+ government" & 0.847 & 3 \\
\hline Total questionnaire & 0.940 & 22 \\
\hline
\end{tabular}

Then KMP (Kaiser Meyer Olkin) and Bartlett spherical test were used to test the validity of the questionnaire data. The KMO value of the trust system is 0.927, and the Chi-square value of the Bartlett spherical test is 7937 (820 degrees of freedom). The test results shown in Table 3 as follows: the Bartlett spherical test in the table is 0.000 , and the result shows that the questionnaire data has good correlation and could be used for factor analysis

Table 3 Test of KMO and Bartlett in trust system

\begin{tabular}{lll}
\hline Adequacy of Kaiser-Meyer-Olkin Sampling & .927 \\
\hline \multirow{3}{*}{ Bartlett spherical test } & chi-square & 7937.058 \\
& df & 820 \\
& Sig. & .000 \\
\hline
\end{tabular}

4.2.2 Confirmatory factor analysis

The method of principal component analysis is used for confirmatory factor analysis, and the items with factor loading value greater than 1 or less than 0.5 were excluded. In the process of principal component factor analysis, the items with factor loading coefficient less than 0.5 are eliminated, which makes the data of the questionnaire have good convergence validity. The confirmatory factor analysis of trust factors is shown in Table 4.

Table 4 Confirmatory Factor Aanalysis

\begin{tabular}{|c|c|c|c|c|}
\hline $\begin{array}{l}\text { potential } \\
\text { variable }\end{array}$ & factor loading & potential variable & item & factor loading \\
\hline
\end{tabular}




\begin{tabular}{|c|c|c|c|c|c|}
\hline \multirow[t]{4}{*}{ Trust Tendency } & TP1 & 0.726 & perceived & TO1 & 0.842 \\
\hline & TP2 & 0.703 & \multirow[t]{3}{*}{ information disclosure } & TO2 & 0.813 \\
\hline & TP3 & 0.701 & & TO3 & 0.797 \\
\hline & TP4 & 0.626 & & TO4 & 0.815 \\
\hline perceived trust & TI1 & 0.745 & \multirow{4}{*}{$\begin{array}{l}\text { perceived trust in } \\
\text { information serviceability }\end{array}$} & TS1 & 0.726 \\
\hline in information & TI2 & 0.740 & & TS2 & 0.703 \\
\hline \multirow[t]{2}{*}{ security } & TI3 & 0.686 & & TS3 & 0.701 \\
\hline & & & & TS4 & 0.744 \\
\hline Government & TG1 & 0.804 & Adoption & AD1 & 0.78 \\
\hline \multirow[t]{3}{*}{ Trust } & TG2 & 0.793 & \multirow[t]{3}{*}{ "Internet+ overnment" } & AD2 & 0.81 \\
\hline & TG3 & 0.826 & & AD3 & 0.75 \\
\hline & TG4 & 0.772 & & & \\
\hline
\end{tabular}

4.2.3 Structural model analysis

By using the structural equation model and LISREL tool, the path coefficient on each potential variable of the factors that influencing government trust was analyzed. (see Table 5). From the table, we can see that the public's trust in the government will affect the public's willingness to adopt, and the path coefficient is 0.53 . As shown in Figure 2, the public's trust in information disclosure, information security and information serviceability will directly affect the government's trust, while trust tendency indirectly affects the government's trust.

Table 5 Path analysis and verification results of structural equation

\begin{tabular}{|l|l|l|l|l|}
\hline Hypothesis & Relationship & Path & significance & Result \\
\hline Hypothesis H1 & TG->AD & 0.53 & 0.000 & Support \\
\hline Hypothesis H2 & TO->TG & 0.52 & 0.000 & Support \\
\hline Hypothesis H3 & TI->TG & 0.46 & 0.000 & Support \\
\hline Hypothesis H4 & TS->TG & 0.43 & 0.001 & Support \\
\hline Hypothesis H5 & TP->TO & 0.39 & 0.006 & Support \\
\hline Hypothesis H6 & TP->TI & 0.41 & 0.003 & Support \\
\hline Hypothesis H7 & TP->TS & 0.42 & 0.002 & Support \\
\hline Hypothesis H8 & TP->TG & 0.10 & 0.086 & Not Support \\
\hline
\end{tabular}

By using the structural equation model and LISREL tool, the path coefficient on each potential variable of the factors that influencing government trust is carried out, and the measured value of government trust factors is shown in Figure 2 .

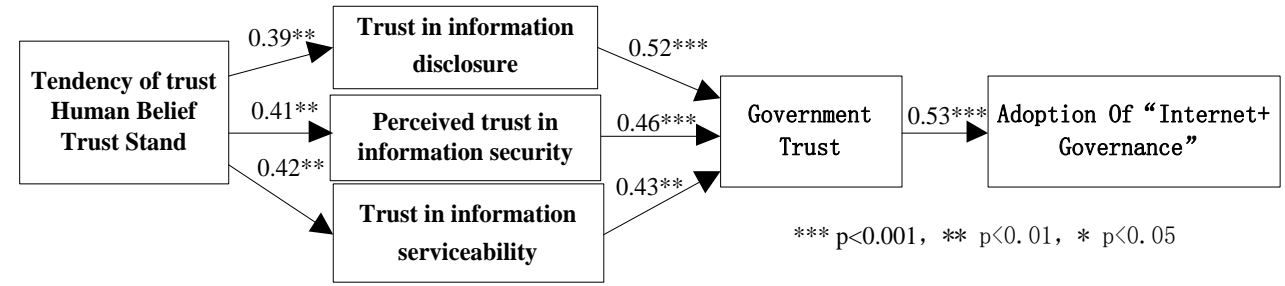

Fig 2: Path coefficient of trust factors

4.4 T-test whether there are significant differences in trust between different genders

The public's trust in information disclosure, information security and information serviceability will directly affect the government's trust. In the paper gender was used as a control variable to observe their influence on government trust, in the effective questionnaire, $57 \%$ were men and $43 \%$ were women. Independent sample t-test was used to analyze whether there was significant difference between male and female. In the specific calculation, we need to complete two steps: firstly, use F-test to judge whether the variance of two populations is the same; secondly, according to the results of the first step, determine the calculation formula of t-statistics and degree of freedom, and

ISSN: 0010-8189 
then judge the conclusion of t-test.

This paper uses the Levene F method of SPSS to test whether the two populations have the same variance. Formulas for determining $\mathrm{t}$-statistics and degrees of freedom:

4.4.1 When the variance of two populations is unknown and the same, the formula of $\mathrm{t}$ statistic is below formula (1):

$$
t=\frac{x_{1}-x_{2}}{\sqrt{s_{p}^{2} / n_{1}-s_{p}^{2} / n_{2}}}
$$

In the formula (1)

$$
s_{p}^{2}=\frac{\left(n_{1}-1\right) s_{1}^{2}+\left(n_{2}-1\right) s_{2}^{2}}{n_{1}+n_{2}-1}
$$

Here t-statistics obey the t-distribution of $n_{1}+n_{2}-1$ degrees of freedom, as formula (2)

4.4.2 When the variance of two populations is unknown and different, the formula of t statistic is below formula (3):

$$
t=\frac{\overline{x_{1}}-\overline{x_{2}}}{\sqrt{s_{1}^{2} / n_{1}+s_{2}^{2} / n_{2}}} \ldots
$$

$\mathrm{T}$ statistic still obeys $\mathrm{t}$ distribution, and the modified degree of freedom is used to calculate the degree of freedom, as formula (4)

$$
f=\frac{\frac{s_{1}^{2}}{n_{1}}+\frac{s_{2}^{2}}{n_{2}}}{\frac{\left(\frac{s_{1}^{2}}{n_{1}}\right)^{2}}{n_{1}}+\frac{\left(\frac{s_{2}^{2}}{n_{2}}\right)^{2}}{n_{2}}} .
$$

From the calculation formula of $\mathrm{T}$ statistics in two cases, it can be seen that if the difference between the mean values of the two samples to be tested is small and the $\mathrm{T}$ value is small, it means that there is no significant difference between the mean values of the two samples; on the contrary, the larger the $\mathrm{T}$ value is, it means that there is a significant difference between the mean values of the two samples.

The public's trust in information disclosure, information security and information serviceability between different genders, as below Table6 Table7: 
Table6 Group Statistics

\begin{tabular}{|c|c|c|c|c|c|}
\hline & Sex & $\mathrm{N}$ & Mean & Std.Deviation & $\begin{array}{l}\text { Std.Error } \\
\text { Mean }\end{array}$ \\
\hline $\begin{array}{l}\text { The public's trust in the } \\
\text { government will affect the } \\
\text { public's willingness to } \\
\text { adopt.The public's } \\
\text { perceived trust in the } \\
\text { transparency of } \\
\text { government information. }\end{array}$ & Female & $\begin{array}{l}1715 \\
1293\end{array}$ & 4.00 & .606 & $\begin{array}{l}.032 \\
.028\end{array}$ \\
\hline $\begin{array}{l}\text { The perceived trust in the } \\
\text { public on the } \\
\text { transparency of } \\
\text { information disclosure } \\
\text { will affect the public's trust } \\
\text { in the government. }\end{array}$ & Female & $\begin{array}{l}1715 \\
1293\end{array}$ & $\begin{array}{l}4.36 \\
4.23\end{array}$ & .480 & $\begin{array}{l}.025 \\
.024\end{array}$ \\
\hline $\begin{array}{l}\text { The public's perceived } \\
\text { trust in information } \\
\text { security will affect the trust } \\
\text { in the government. }\end{array}$ & $\begin{array}{l}\text { Male } \\
\text { Female }\end{array}$ & $\begin{array}{l}1715 \\
1293\end{array}$ & $\begin{array}{l}4.05 \\
4.28\end{array}$ & $\begin{array}{l}.704 \\
.458\end{array}$ & $\begin{array}{l}.037 \\
.026\end{array}$ \\
\hline
\end{tabular}

Teate? indepensent Saruiles test

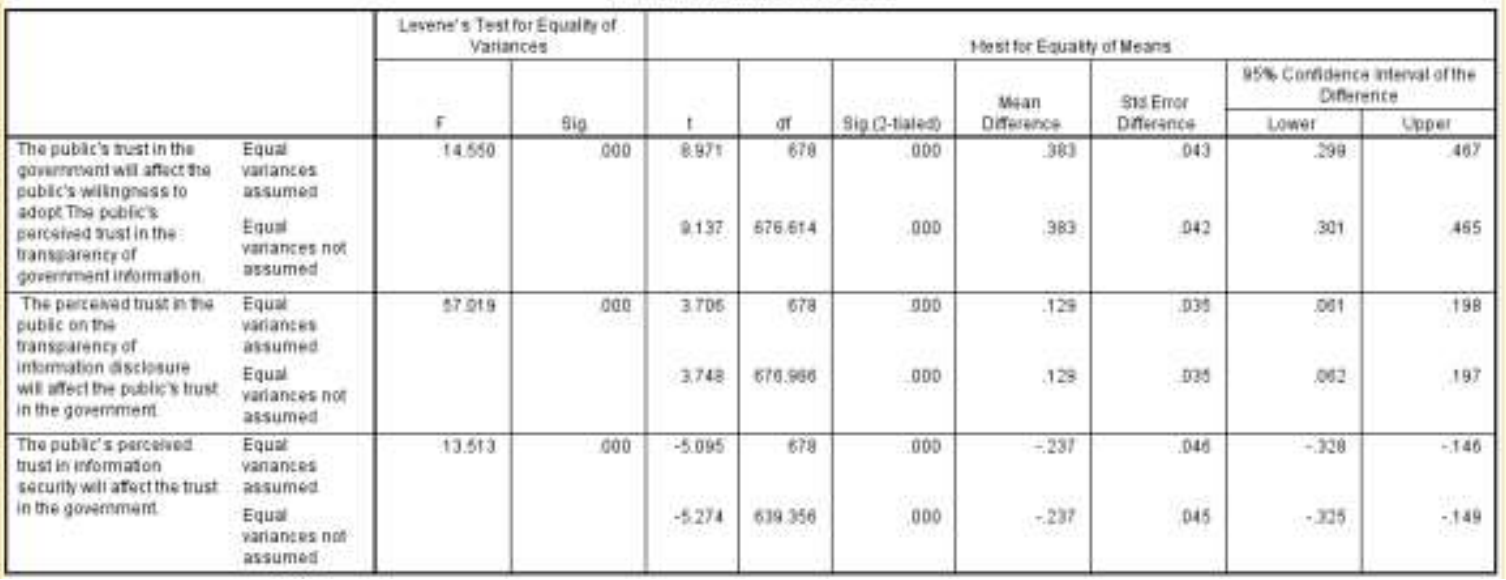

Conclusion: it shows that there are significant differences in government trust between different genders. The government should provide diversified services for men and women when providing government services.

\section{Discussion of Results}

Based on the path coefficient of the above structural equation model: The perceived trust path coefficient of the public to the openness and transparency of information content are 0.52 , which shows that the openness and transparency of government information significantly affect the public's trust in the government. At the same time, the features such as modification-proof, traceability, transparency, and credibility of block-chain are consistent with the perceived trust of the public. Adopting block-chain technology to innovate the government service model, so as to realize an openness, transparency, and credibility of information resources, will encourage the public to acknowledge and understand the government's behavior, improve the transparency and availability of information, reduce the cost of communication between the government and the public, improve their relationship, enhance the public's understanding and positive evaluation on government's behavior, so as to increase the public's trust in the government.

The path coefficient of the public to information security is 0.46 , which indicates that the public's perceived trust in information security has a positive impact on the government's trust. If users believe that the government data platform and information environment are safe, they will actively adopt the "Internet+ government" service, actively use the platform to handle various transactions, and conduct various interactive activities. Therefore, the government

ISSN: 0010-8189 
needs to create a legal and safe Internet environment to increase public trust in the "Internet+ government" environment. block-chain's hashing algorithm and asymmetric encryption algorithm can verify data sources, protect data security, and prevent data leakage. The point to point technology of block-chain can prevent the distortion and lag of government data, thereby promising the data consistency and integrity. In short, the security of government information platform can be enhanced by using block-chain technology, which can increase public trust in the "Internet+ government" service platform, thereby increasing public trust in government information service capabilities and network environment.

The public trust path coefficient of government information service capacity is 0.43 , which indicates that public perception of trust in government information service capability positively affects the trust in government, which indicates that the development of the "Internet+ government" affairs highly depends on public trust in government information service capability. By using the new features of block-chain to optimize the government service process, promote the diversification and refinement of public services, government can provide the public with efficient, accurate and convenient services beyond the time and space constraints at a lower cost, which is help to the public to form a positive understanding of public management activities and public services, improve the relationship between the public and the government, fundamentally builds the solid base of government trust.

The path coefficient of trust tendency is 0.10 , which indicates that the trust tendency belongs to individual attributes has no direct impact on government trust. According to the results of path analysis, trust tends can influence public trust in information quality, in government information serviceability, and in the application of block-chain technology. Therefore, government agencies can compose policies to encourage more public to use the "Internet + government" services, and once users perceive the efficiency, convenience, and interaction brought by the online services, there will also be a change of trust tendency, and people will gradually improve their trust in the network environment, the government's information serviceability, and the block-chain technology, thus will increase their trust in the government. At the same time, we should improve the serviceability and integrity of government agencies, improve the trust relationship between the public and the government, enhance the overall trust of the public in the government agencies, and ultimately the public will accept and use the Internet+ government services better.

This paper analyzes the mechanism of influencing government trust in the context of the coronavirus pandemic and analyzes the cognitive characteristics of public trust from a multidimensional perspective, to help build a government trust system based on block-chain technology. "Internet+ government" affairs are not only a place for expressing public feeling and opinion but also a way to facilitate communication between the government and the public. Under the pandemic background, the "Internet+ government" network ecological should be standardized by block-chain technology, which helps to develop openness and transparency of government information and rebuild the government trust.

\section{Deficiency and Prospect of Research}

In major epidemics, accurate information disclosure is conducive to enhancing the credibility of the government. By using blockchain information technology and taking the opportunity of building a service-oriented government, we can make the government service process transparent, timely disclose all kinds of information related to the epidemic, eliminate social panic, and enhance public confidence and government trust. This paper analyzes the influence mechanism of government trust in the post epidemic period, and analyzes the cognitive characteristics of public trust in government from a multi-dimensional perspective, so as to build a government trust system based on blockchain technology. On the one hand, through the application of blockchain technology, the government improves the efficiency and transparency of information disclosure, and enhances the public's trust in the government; On the other hand, using the block chain decentralization to change the traditional government service mode, build a multi -center collaborative mode, realize the benign interaction and mutual trust of multiple subjects, and maintain the government trust ecology. 
Due to the limitations of research environment and conditions, this paper also has the following deficiencies: Firstly, although the sample involves different occupations, different ages and different education levels of the public, the limitations of the sample size are inevitable, and the universality of the research results needs further empirical test; Secondly, the research data is mainly cross-sectional data, which is difficult to study the relationship between variables from the time dimension; Thirdly, it is an important content of government governance innovation to use the advantages of blockchain technology to improve the efficiency of information disclosure, which puts forward new challenges for the relevant theoretical research and practical exploration. This paper only carries out part of the work on this topic. In the later stage, we should further study the impact and effectiveness of public participation and information disclosure and other related variables, and strengthen the longitudinal time series research to improve the systematicness and integrity of the research.

\section{Acknowledgements}

Key research project of Humanities and Social Sciences in Anhui Province (sk2019a0650); Doctoral start-up fund project of Anhui Jianzhu University (2018qd24); Anhui quality engineering project (2019kfkc095); Anhui social science innovation and development project "Application of blockchain technology in response to epidemic situation and government governance" (2020CX042);Anhui philosophy and social science project "Research on the information disclosure demand in major emergencies and its relationship with the trust of government" (AHSKY2020D13); Ministry of Education Collaborative Education Project: 202002237018.

\section{Reference}

[1] M. Cyan, M. Price, M. Rider, "What determines citizen trust: evaluating the impact of campaigns highlighting government reforms," International Center for Public Policy Working Paper, 2017.

[2] D.H. McKnight, N.L. Chervany, "What trust means in e-commerce customer relationships: an interdisciplinary conceptual typology," International Journal of Electronic Commerce, vol. 6, no. 4, pp. 35-60, 2002.

[3] L.W. Wang, "E-government Trust: version 2.0 of government trust in the digital era," E-government, vol. 10, pp. 7-14, 2015.

[4] J.P. Liu, Y. Zhou, "Concept, influencing factors, change mechanism and role of government trust," Guangdong Social Sciences, no. 6, pp. 85-91, 2017.

[5] V. Venkatesh, F.D. Davis, M.G. Morris, "Dead or alive? the development, trajectory and future of technology adoption research,” Ais Educator Journal, no. 4, pp. 267-286, 2007.

[6] M. Cyan, M. Price, M. Rider, "What determines citizen trust: evaluating the impact of campaigns highlighting government reforms," International Center for Public Policy Working Paper, 2017.

[7] G.Q. Rui, D. Song, G.Q. Rui, et al., "Research on the relationship between E-government and government trust - Taking citizen satisfaction as the intermediary variable," Nanjing Social Sciences, no. 2, pp. 82-89, 2015.

[8] C.K. Zhu, W.L. Mao, W. Li, “Can the use of e-government improve public government trust?” Public Management and Policy Review, no. 4, pp. 60-70, 2017.

[9] X. Lu, R.M. Pei, F. Liu, "Influencing factors and security risk analysis of E-government information resource sharing,” Management review, vol. 25, no. 6, pp. 161-169, 2013.

[10] T.H. Que, "Research on Information security countermeasures of Fujian provincial government portal website,” E-government, no. z1, pp. 36-38, 2008.

[11] Y.M. Yu, T.W. Chen, Z.T. Duan, "Research on government information resource sharing model based on blockchain. E-government, no. 4, 2019.

[12] L. Ma, "How the use of E-government affects Citizen Trust: the mediating effect of government transparency and response," Public Administration Review, no. 6, pp. 51-70 + 203.

[13] J.P. Liu, Y. Zhou. "Concept, influencing factors, change mechanism and role of government trust," Guangdong Social Sciences, no. 6, pp. 83-89, 2017.

[14] "Science and technology in Beijing: challenges in science and technology," Journal of science and 
technology of China (j.05).

[15] Y. Zhang, Y. Zhu, "System trust based on blockchain technology: a trust decision analysis framework," E-government, no. 8, pp. 117-124, 2019.

[16] C.G. Zhang, "Blockchain era: technological development, social change and risk challenges," People's Forum Academic Frontier, no. 12, pp. 33-43, 2018.

[17] R.X. Bi, "Research on E-government based on blockchain," China Management Informatization, vol. 19, no. 23, pp. 148-151, 2016.

[18] M.L. Wang, J.Y. Lu, "Blockchain technology and its application in government governance," E-government, vol. 15, no. 2, pp. 2-14, 2018.

[19] M. Ren, H.B. Tang, X.M. Si, et al., "Application of blockchain technology in government departments," Computer science, vol. 45, no. 2, pp. 1-7, 2018.

[20] V. Venkatesh, F.D. Davis, M.G. Morris, "Dead or alive? The development, trajectory and future of technology adoption research," Ais Educator Journal, vol. 8, no. 4, pp. 267-286, 2007.

[21] M. Cyan, M. Price, M. Rider, "What determines citizen trust: evaluating the impact of campaigns highlighting government reforms," International Center for Public Policy Working Paper, 2017.

[22] D.G. Zhu, J.H. Guo, "Internet plus government adoption model and empirical analysis based on UTAUT model," Information Science, vol. 34, no. 9, pp. 110-114, 2016.

[23] L. Qian, Y. Wang, "Research on the public adoption model of "internet + government affairs" service," Information Science, vol. 34, no. 10, pp. 141-146, 2016.

[24] X.L. Xu, Z.Y. Zhang, C.H. Ming., "Public trust, government service quality and sustainable use intention: An Empirical Study Based on PLS-SEM," Executive Forum, vol. 26, no. 3, 2019. 